\title{
At-Risk Persons' Attitudes Toward Presymptomatic and Prenatal Testing of Huntington Disease in Michigan
}

\author{
Dorene S. Markel, Anne B. Young, and John B. Penney \\ University of Michigan, Department of Neurology, Ann Arbor, Michigan
}

\begin{abstract}
One hundred fifty-five individuals at $50 \%$ risk of inheriting Huntington disease (HD) were given a questionnaire surveying their sociodemographic characteristics, experience with HD, and attitudes toward presymptomatic and prenatal testing in HD. About two-thirds (63.2\%) of the persons indicated they would take a presymptomatic test even if no specific treatment was available. Although onehalf $(49 \%)$ of the respondents stated they would make use of a prenatal test, only $43 \%$ of these individuals would decide to terminate a heterozygous fetus. Presympatomatic test results indicating carrier status would influence some of the respondents' decisions about marriage and childbearing. This strong interest of atrisk persons to make use of both presymptomatic and prenatal diagnosis in HD indicates the need for well-organized testing programs. These programs must be designed to address the genetic, psychosocial, and ethical issues that may arise in the use of this type of genetic test.
\end{abstract}

Key words: Huntington disease, predictive testing, presymptomatic testing, prenatal testing, autosomal dominant inheritance

\section{INTRODUCTION}

Huntington disease (HD) is an adult-onset, neurodegenerative disorder characterized by autosomal dominant transmission [Conneally, 1984]. The disease is untreatable and undetectable until symptoms appear. Children of an affected individual are at $50 \%$ risk of having inherited the HD gene. Since the onset of the disease is usually in adult life, many at-risk persons are forced to make decisions regarding education, careers, marriage and children without knowing if someday they too will be affected by the disease [Wexler, 1979]. Over the years this burden of uncertainty has prompted a search for a reliable predictive test for HD. Recently, a restriction fragment length

Received for publication February 19, 1986; revision received May 19, 1986.

Address reprint requests to Dorene S. Markel, M.S., Department of Neurology, University of Michigan, Neuroscience Laboratory Building, 1103 East Huron Street, Ann Arbor, MI 48104-1687.

(C) 1987 Alan R. Liss, Inc. 
polymorphism (RFLP) was identified that is closely linked to the HD gene locus and will allow presymptomatic and prenatal diagnosis in HD persons with the appropriate family structure and size [Gusella et al, 1983, 1984].

Many studies were undertaken before the discovery of this genetic marker to assess the attitudes and interest of persons at-risk for HD toward predictive testing [Barette and Marsden, 1979; Stern and Eldridge, 1975; Teltscher and Polgar, 1981; Tyler and Harper, 1975]. These studies predicted that between $56 \%$ and $80 \%$ of atrisk persons were in favor of a hypothetical predictive test for HD. A study conducted since the marker discovery found that $73 \%$ of at-risk persons wanted to be tested [Schoenfeld et al, 1984].

Since use of the marker test is expected to begin soon, we have conducted a study attempting to assess the demand and impact of such a test in the State of Michigan. The influence that predictive testing in HD will have on attitidues toward marriage, childbearing, and pregnancy outcome were examined, and the relationships between social and demographic variables and those attitudes were tested.

\section{MATERIALS AND METHODS}

A 30-item anonymous questionnaire was distributed throughout the State of Michigan between January 1984 and August 1985. These questionnaires were sent to approximately 1,200 individuals on the mailing lists of the Michigan Chapter of the Huntington's Disease Foundation of America (HDFA) and the Michigan Chapter of the National Huntington's Disease Association (NHDA). Questionnaires were also distributed to HD relatives seen for genetic counseling at the University of Michigan's Movement Disorders Clinic. Persons were asked to identify which of the following groups applied to them: a) affected by $\mathrm{HD}$, b) $50 \%$ at risk (child of an affected parent), c) spouse of a person affected by HD; d) spouse of a person at $50 \%$ risk, e) $25 \%$ at risk (grandchild of person with $\mathrm{HD}$ ), and f) other. Of the 258 questionnaires that were returned 155 were completed by persons at $50 \%$ risk, 15 by affected individuals, 32 by spouses of HD patients, 34 by spouses of persons at $50 \%$ risk, 14 by $25 \%$ at-risk individuals and 8 by others.

The questionnaire included 22 multiple choice questions and 8 questions that required a numerical answer. Of these questions, 28 were appropriate for persons at $50 \%$ risk for $\mathrm{HD}$. The remaining two questions were aimed at HD and at-risk spouses only. This study will only examine the responses of the 155 questionnaires returned by those at $50 \%$ risk for HD. Responses of the other groups will not be analyzed until a larger sample can be collected.

Subjects were asked about their social and demographic background and the sex, age of onset, age of diagnosis, and survivorship of their affected parent. Additional questions covered the following topics: 1) the age at which the subject learned the hereditary implication of $\mathrm{HD} ; 2$ ) the number of affected relatives; 3 ) the frequency of contact with affected relatives; 4) the subject's best source of information about HD; 5) the subject's attitude toward taking a presymptomatic test; 6) the subject's attitude toward having one's child(ren) tested; 7) the effect of a positive presymptomatic test on subsequent decisions about marriage, childbearing, and pregnancy outcome; 8) the subject's attitude toward use of a prenatal test; and 9) the effect of a positive prenatal test on pregnancy outcome decisions. A chi-square analysis was performed to test the significance of association between the variables. 
TABLE I. Social and Demographic Information

\begin{tabular}{lrr}
\hline & $\mathrm{N}$ & Percent \\
\hline Sex & & \\
Male & 52 & 33.5 \\
$\quad$ Female & 103 & 66.5 \\
Marital status & & \\
$\quad$ Never married & 29 & 18.7 \\
Married & 111 & 71.6 \\
Separated/divorced & 13 & 8.4 \\
Widowed & 2 & 1.3 \\
Number of children & & \\
None & 49 & 31.8 \\
One & 22 & 14.3 \\
Two & 35 & 22.7 \\
Three & 23 & 14.9 \\
Four & 16 & 10.4 \\
Five or more & 9 & 5.8 \\
(Left blank) & $(1)$ & \\
Education & & \\
<High school grad & 18 & 11.7 \\
High school grad & 55 & 35.7 \\
Some college & 38 & 24.7 \\
College grad & 20 & 13.0 \\
Postgraduate & 14 & 9.1 \\
Vocational training & 9 & 5.8 \\
(Left blank) & $(1)$ & \\
Religion & & \\
Catholic & 66 & 43.7 \\
Protestant & 16 & 45.0 \\
Jewish & 16 & 10.6 \\
Other & $(4)$ & \\
(Left blank) & & \\
\hline
\end{tabular}

\section{RESULTS}

Questionnaires were received from 155 persons at $50 \%$ risk for Huntington disease. Most of the questionnaires were fully completed, although a number of respondents left some questions unanswered.

\section{Sociodemographic Information}

The sociodemographic information provided by the at-risk respondents is given in Table I. The mean age of these persons is 38.2 ( $\mathrm{SD}=13.8)$. Ten $(9.7 \%)$ of the 105 respondents who already had children, reported they planned to have more, with one $(1.0 \%)$ respondent being uncertain, and $92(89.3 \%)$ choosing not to increase their family size; 2 individuals did not complete this question. Respondents with offspring had a mean of $2.6(\mathrm{SD}=1.3$ ) children. Of the unmarried, childless respondents, $8(30.8 \%)$ planned children in the future, $5(19.2 \%)$ did not, and 13 $(50.0 \%)$ were uncertain. Among the childless, married respondents, $6(33.3 \%)$ planned children in the future, $7(38.9 \%)$ chose to remain childless, and $5(27.8 \%)$ were uncertain. 


\section{Experience with Huntington Disease}

Ninety-three $(60.0 \%)$ respondents had a mother affected by HD, $58(37.4 \%)$ had an affected father, and $4(2.6 \%)$ did not know which parent had been affected. Fifty-five (35.5\%) had a living affected parent, while $96(61.9 \%)$ reported a deceased affected parent; 4 (2.5\%) individuals did not answer this question. The mean reported age-of-onset of the respondents' affected parent was $42.2 \mathrm{yr}(\mathrm{SD}=8.8)$, while the mean age of diagnosis was $47.7 \mathrm{yr}(\mathrm{SD}=9.5)$. When asked if they had lived with their parent while he/she was affected, $107(69.0 \%)$ respondents answered they had lived with the affected parent, $42(27.1 \%)$ had not, and $6(3.9 \%)$ did not answer this question.

Only one $(0.7 \%)$ respondent had never known a relative affected by HD (due to adoption), while 57 (39.6\%) knew 1 to 2 affected relative(s), 55 (38.2\%) knew 3 to 4 affected relatives, and $31(21.5 \%)$ knew 5 or more affected relatives; 11 persons failed to respond to this question.

The mean age at which the respondents learned about the hereditary implications of $\mathrm{HD}$ was at $20.7 \mathrm{yr}(\mathrm{SD}=10.6)$. Seventy-five $(51.4 \%)$ respondents learned that HD was hereditary before they became 18 years old. Of the respondents with children, $62(59.0 \%)$ had learned of the hereditary nature before having children.

The respondents felt their best sources of information about HD were their own reading $(29.3 \%)$, their relatives $(26.9 \%)$, lay organizations $(23.7 \%)$, physicians $(13.9 \%)$, other health professionals $(4.1 \%)$, and other sources $(2.0 \%)$.

\section{Attitudes Toward Presymptomatic Testing}

In response to the question "If a reliable predictive test were to become available which would show whether or not you had the gene for HD, but no treatment was available, would you want to take this test?", $98(63.2 \%)$ responded yes, $24(15.5 \%)$ said no, $30(19.4 \%)$ were uncertain, and $3(1.9 \%)$ did not respond to the question. However, asked if they would use the same test if treatment were available, 134 $(86.5 \%)$ responded yes, $3(1.9 \%)$ responded no, $14(9.0 \%)$ were uncertain, and 4 (2.9\%) did not complete the question.

The sociodemographic and $\mathrm{HD}$ experience variables were examined to determine whether any variable correlated using a chi-square analysis with one's attitude toward presymptomatic testing. Of these, the number of affected relatives correlated positively with the number of individuals who desired to be tested in the case when no treatment for HD was available $(p<.05)$. Also, the earlier the parent's age of onset, the more willing the respondents were to take a predictive test $(p<.05)$. All other variables tested were independent of the respondent's attitude toward a presymptomatic test.

Of those with children, $70(66.7 \%)$ wanted them tested, $9(8.6 \%)$ did not, and $26(24.8 \%)$ were uncertain. The age of the respondents was correlated with their attitude toward predictive testing in their children. The older the respondent, the more likely they were to want their children tested $(p<.01)$. Since the age of the respondents' children were not assessed, it could be assumed that the older the respondent, the older the respondents' children. In the case of nonminor children the wishes of the parent would not be considered important. 


\section{Effects of a Positive Presymptomatic Test Result}

Asked how a positive test result would have (had) influenced the respondents' decisions about marriage, $17(11.0 \%)$ stated they would (will) have been deterred from marrying, $62(40.0 \%)$ said they would not be deterred, $66(42.6 \%)$ were unsure, and $10(6.5 \%)$ failed to respond to the question. No variable collected was associated with respondents' attitudes toward marriage.

Sixty-six $(42.6 \%)$ said a positive test result would deter them from having children, $25(16.1 \%)$ said it would not, $47(30.3 \%)$ were unsure, and $17(11.0 \%)$ failed to answer. Of the childless respondents planning to have children, $3(21.4 \%)$ indicated they would be deterred by a positive test result, $4(28.6 \%)$ would not, 4 . $(28.6 \%)$ were uncertain, and $3(21.4 \%)$ did not answer. Of at-risk persons with children planning to have more, one (10.0\%) said they would be deterred by a positive result, $4(40.0 \%)$ would not, and $5(50.0 \%)$ were uncertain. Of respondents with children not planning to have more, $39(42.4 \%)$ said a positive test result before they had had children would have deterred them, $17(18.5 \%)$ would not have been deterred, $32(34.8 \%)$ were unsure, and $4(4.3 \%)$ did not complete the question.

Two variables showed a significant correlation with one's attitude toward childbearing after a positive presymptomatic test result. The level of education was correlated positively with a respondents' indication that a positive test result would deter him/her from childbearing $(\mathrm{p}<.01)$. The number of affected relatives also correlated significantly with the respondents' childbearing decisions. Those respondents with five or more affected relatives were more likely to be deterred from childbearing by a positive test result than those with less than five affected relatives $(\mathrm{p}<.05)$.

If a pregnancy occurred after the respondent had had a positive test result, 73 $(41.1 \%)$ stated they would want to complete the pregnancy, 21 (13.5\%) would terminate the pregnancy, $39(25.2 \%)$ were unsure, and $22(14.2 \%)$ failed to complete the question. A significant correlation was found when the responses were categorized by religious preference. Catholics were more likely to choose to complete a pregnancy. than Protestants $(\mathrm{p}<.05)$; Protestants were four times as likely to favor pregnancy termination than the Catholics. The data also showed that persons who would not deter childbearing after the parent had a positive test were almost three times more likely to complete a pregnancy than those who chose to deter childbearing $(\mathrm{p}<.05)$. There were $22(34.9 \%)$ of the deterred childbearing group who would complete the pregnancy, $21(33.3 \%)$ who would terminate the pregnancy, and $20(31.7 \%)$ who were unsure. In the undeterred group, $24(96.0 \%)$ would complete the pregnancy, 0 $(0 \%)$ would choose an abortion, and $1(4.0 \%)$ was unsure. Among those unsure of their childbearing decisions, $25(58.1 \%)$ would complete the pregnancy, $0(0 \%)$ would want an abortion, and $18(41.9 \%)$ were unsure.

\section{Attitudes Toward Prenatal Testing}

Seventy-six (49.0\%) respondents said they would (or would have) use(d) a prenatal test if available, $20(12.9 \%)$ stated they would not, $34(21.9 \%)$ were uncertain, and $25(16.1 \%)$ did not complete the question. The only variable that 
appeared to influence the respondents' attitudes toward the use of a prenatal test was religious preference. Catholics differed little from the group as a whole or from Protestants as to the percentage choosing not to favor a prenatal test but showed a significant decrease compared to the other groups in the number favoring such a test and an increase in the number that was uncertain $(p<.05)$.

\section{Effect of a Positive Prenatal Test}

When asked to make a decision about the outcome of a pregnancy if a prenatal test was positive, $52(33.5 \%)$ indicated they would complete the pregnancy, 35 $(22.6 \%)$ stated they would want an abortion, 46 (29.7\%) were unsure, and $22(14.2 \%)$ did not complete the question. The responses of Catholics and Protestants to this question were very similar.

Of the persons who said they would take a prenatal test, given a positive result $17(22.7 \%)$ indicated they would complete the pregnancy, $32(42.7 \%)$ would choose an abortion, and $26(34.7 \%)$ were uncertain about their decision. As expected, respondents with and without children were significantly more in favor of terminating a pregnancy when a prenatal HD test is positive than when deciding solely on the basis of their own positive test result $(p<.001)$. This study did not ascertain the number of respondents that would choose to abort a pregnancy regardless of any predictive procedure.

\section{DISCUSSION}

This survey indicates that about two-thirds of the respondents plan to make use of a presymptomatic test for $\mathrm{HD}$, even when no treatment for this disease is available. This finding is consistent with those of other similar studies [Barette and Marsden, 1975; Schoenfeld et al, 1984; Stern and Eldridge, 1975; Teltscher and Polgar, 1981; Tyler and Harper, 1975]. In the event that some kind of treatment becomes available the number of respondents requesting the test would increase dramatically. The two variables that correlated with a person's desire to be tested were the number of affected people in one's family and the parent's age of onset. A person with many affected relatives may feel more at risk, or that their lives have been more impacted upon by HD, and thus have a greater need to know their own status. Respondents whose parent had an earlier onset also were more likely to want to be tested, suggesting that those who are at risk and anticipate an earlier onset in themselves, may have more of a need to know their status than individuals from families where most affected relatives had onset later in life. Although only $11 \%$ of respondents with a positive test stated they would be deterred from marrying, almost one half were unsure about marriage suggesting that those who test positive are going to face increased uncertainty about important issues in their lives.

Two-thirds of the respondents wanted their children to be tested. However, since our questionnaire did not ascertain what proportion of these children were minors, it was not possible for us to determine what the demand for the testing of minors will be. If there is a demand for the testing of minors this may create a conflict between the HD family and the testing center. In preliminary discussions about organizing a testing program, many centers including our own do not plan to test minors. A decision with such overwhelming implications for one's future should only 
be made by that person him/herself when they reach adulthood. The rearing of children whose parents know their HD status could be affected negatively.

Almost one-half of respondents would be deterred from having children if the at-risk person had a positive test. However, of the respondents who actually plan to have more children, many fewer $(16.7 \%)$ would be deterred from childbearing. It is interesting that most persons with completed families indicated they would not have had children having known of a positive presymptomatic test result. It is not known if these respondents would actually have felt this way before childbearing or if it is simply easier for them to choose this response retrospectively. However, although a precise estimate is difficult to make, the data suggest there will be a decrease in the number of children born to test-positive parents.

When a person with a positive test result is faced with a pregnancy almost one half stated they would complete the pregnancy, few would choose an abortion, and almost one quarter were undecided. Also, although almost one half the respondents indicated they would (or would have) make use of a prenatal test, less than one-half of this group would choose to terminate a pregnancy when a positive prenatal result is obtained, about one quarter would choose to continue the pregnancy, and about one third was uncertain. These results indicate that the gene frequency in the next generation would be decrease to some extent by this selective abortion process. It also indicates a major area of concern in presymptomatic and prenatal testing. Many persons will be bearing children they know have $50 \%$ risk or have been identified as being probable HD heterozygotes. How parents will deal psychologically with this knowledge is unknown. Many children may have to grow up with the knowledge that they will have a fatal disease. Furthermore, the knowledge of the child's HD status may negatively influence their upbringing.

Although presymptomatic and prenatal diagnosis may answer some questions of the person at-risk for HD, they will likely create many other uncertainties. It is difficult to anticipate just how this test will affect the at-risk person, but testing centers need to be prepared to deal with these issues. Counseling needs to be provided to atrisk individuals during the decision-making and coping processes before the test, while waiting for the test result and afterwards. Not only should those with positive or uncertain test results receive posttest counseling, but those with negative test results should also since each test outcome is likely to have dramatic impact on one's life. Those found not to have the gene may experience "survivor guilt" since they may have escaped the disease while close relatives may have not [Wexler, 1984].

Much preparation needs to be undertaken to provide a comprehensive testing program for presymptomatic and prenatal testing. Centers should be prepared to address not only the genetic issues, but also the psychosocial issues facing persons at risk for $\mathrm{HD}$, before any testing is implemented.

\section{ACKNOWLEDGMENTS}

The authors wish to thank Zane Hollingsworth for his assistance in data analysis, the Michigan Chapter of the Huntington's Disease Foundation of America and the Michigan Chapter of the National Huntington's Disease Association for distribution of questionnaires, and Jan Pappas for manuscript preparation. This work was supported by USPHS grant NS 15655 and the Huntington's Disease Foundation of America. 


\section{APPENDIX}

SURVEY OF ATTITUDES TOWARD HUNTINGTON DISEASE TESTING

\section{PART A: TO BE COMPLETED BY EVERYONE.}

1. Who are you?
a. affected with HD
b. $50 \%$ at-risk for HD (child of an affected parent)
c. spouse of person affected by HD
d. spouse of person $\mathbf{5 0 \%}$ at-risk for $\mathrm{HD}$
e. $25 \%$ at-risk for HD (grandchild of an affected grandparent)

2. What is your sex?
a. male
b. female

3. What is your age? years old.

4. What is your marital status?
a. never married
b. married
c. separated
d. divorced
e. widowed

5. How many children do you have?

6. If you have no children, are you planning on having them in the future?
a. yes
b. no
c. uncertain

7. If you presently have children do you plan to have more?
a. yes
b. no
c. uncertain

8. If yes in \#7, how many more children do you plan to have?

9. What is the highest level of education that you have completed? (circle only one).
a. less than high school graduate
b. high school graduate
c. some college
d. college graduate
e. post-graduate
f. vocational training 
10. What is your religious preference?
a. Catholic
b. Protestant
c. Jewish
d. Other

PART B: TO BE COMPLETED BY PERSONS AT 50\% RISK FOR HD.

1. If one of your parents has/had Huntington disease, was it your
a. mother
b. father
c. uncertain

2. At what age did this parent first show signs of Huntington disease?
a.
b. uncertain years old

3. At what age was this parent diagnosed with having Huntington disease?
a.
b. uncertain

4. Is your affected parent living?
a. yes
b. no

5. How old were you when you found out that HD is hereditary? years old.

6. Did you live with your HD parent while he/she was affected?
a. yes
b. no

7. How many people in your family have been affected by HD?

8. How many people in your family affected with HD have you interacted with on a fairly regular basis?

9. What has been your best source of information about HD?
a. relatives
b. physicians
c. lay organizations (CCHD, NHDA, HDFA, etc.)
d. own reading
e. other health professional
f. other (specify):

10. If you have children, did you learn that HD was hereditary . . .
a. before having children
b. after having children 
11. If a reliable predictive test were to become available which would show whether or not you had the gene for HD, but no therapy was available, would you want to take the test?
a. yes
b. no
c. uncertain

12. If you have children, would you want them to take this test, when no therapy was available?
a. yes
b. no
c. uncertain

13. If a therapy for HD was available would you want to take this predictive test?
a. yes
b. no
c. uncertain

14. If this predictive test showed you have the gene for $\mathrm{HD}$, what influence would this have (had) on your decisions about marriage?

a. I would be deterred or would have been deterred from getting married.

b. I would not be deterred or would not have been deterred from getting married.

c. I am not sure how this information would influence my decision about marriage.

15. If this predictive test showed that you had the gene for HD, what influence would this have (had) on your decisions about childbearing?
a. I would be deterred or would have been deterred from having children.
b. I would not be deterred or have been deterred from having children.
c. I am unsure.

16. If this predicitive test showed that you had the gene for HD and a pregnancy did occur, what would you want to do?

a. I would want to complete the pregnancy.

b. I would want to abort the pregnancy.

c. I am unsure.

17. If prenatal testing were available which would indicate whether or not a fetus had the gene for HD, would you want to use such a test.
a. yes
b. no
c. uncertain

18. If this prenatal test showed that the fetus had the gene for HD, what would you want to do? 
a. I would want to complete the pregnancy.

b. I would want to abort the pregnancy.

c. I am unsure.

\section{REFERENCES}

Barette J, Marsden CD (1979): Attitudes of families to some aspects of Huntington's chorea. Psychol Med 9:327-336.

Conneally PM (1984): Huntington disease: Genetics and epidemiology. Am J Hum Genet 36:506-526.

Gusella JF, Tanzi RE, Anderson MA, Hobbs W, Gibbons K, Raschtchian R, Gilliam TC, Wallace MR, Wexler NS, Conneally PM (1984): DNA markers for nervous system diseases. Science 225:13201326.

Gusella JF, Wexler NS, Conneally PM, Naylor SL, Anderson MA, Tanzi RE, Watkins PC, Ottina K, Wallace MR, Sakaguchi AY, Young AB, Shoulson I, Bonilla E, Martin JB (1983): A polymorphic DNA marker genetically linked to Huntington's disease. Nature 308:234-238.

Schoenfeld M, Myers RH, Berkman B, Clark E (1984): Potential impact of a predictive test on the gene frequency of Huntington disease. Am J Med Genet 18:423-429.

Stern R, Eldridge R (1975): Attitudes of patients and their relatives to Huntington's disease. J Med Genet 12:217-223.

Teltscher B, Polgar S (1981): Objective knowledge about Huntington's disease and attitudes towards predictive tests of persons at risk. J Med Genet 18:31-39.

Tyler A, Harper PS (1983) Attitudes of subjects at risk and their relatives towards genetic counseling in Huntington's chorea. J Med Genet 20:179-188.

Wexler NS (1979): Genetic "russian roulette": The experience of being "at risk" for Huntington's disease. In Kessler S (ed): "Genetic Counseling: Psychological Dimensions.” New York: Academic Press Inc.

Wexler NS (1984): Huntington's disease and other late onset genetic disorders. In Emery A, Pullen G (eds): "Psychological Aspects of Genetic Counseling." New York: Academic Press Inc.

Edited by John M. Opitz and James F. Reynolds 